\title{
Effect of Aqueous Extract of Rhazyastricta Decne on Citrinin Production and Fungal Biomass by Pencillium notatum and Optimization of Experimental Design Using Response Surface Methodology
}

\author{
Seema Zargar \\ Department of Biochemistry, College of Science, King Saud University, Riyadh, KSA 11495 \\ http://dx.doi.org/10.13005/bbra/2111
}

(Received: 28 March 2016; accepted: 10 May 2016)

\begin{abstract}
Citrinin (Mycotoxin) is hepato and nephrotoxic agent produced by several species of microorganisms like Aspergillus, Penicilliumand Monascus. Citrinin is generally found in stored grains and is mainly found after their harvest. The aim of the present research was to study and optimize the conditions for maximum inhibition of citrinin and fungal biomass by using aqueous leaf extract of Rhazyastricta Decne under laboratory conditions by Pencillium notatum. Optimization of culture conditions was carried out using Box-Behnken method of response surface methodology. Extent of inhibition of citrinin was carried out using HPLC and reduction in fungal biomass was carried out using dry cell weight after comparing with controls. Optimized culture conditions for inhibition as per the point prediction tool were found to be $13.16(\mathrm{mg} / \mathrm{L})$ for concentration of extract of Rhazyastricta Decne, 10 days of incubation period and temperature of $25{ }^{\circ} \mathrm{C}$ for growth of Pencillium notatum. These optimized values of tested parameters were compared with control citrinin production $(286 \mathrm{mg} / \mathrm{L})$ and dry cell weight production (408.65 $\mathrm{mg}$ ). An average of $80.67 \pm 0.75 \%$ inhibition of citrinin and $81.65 \pm 2.56 \%$ of dry cell weight was obtained in an optimized medium at $10^{\text {th }} \mathrm{d}$ of fermentation with $98.41 \%$ and $\mathbf{9 4 . 3 7 \%}$ validity, respectively.
\end{abstract}

Key words: Pencillium notatum, Citrinin, fungal biomass, Rhazyastricta Decne, Box-Behnken design, Response Surface Methodology.

Mycotoxins, a group of structurally diverse secondary metabolites produced by various fungi, are toxic compounds that contaminate foodstuffs, crops or stored cereals. The ingestion of these contaminated materials in several foods may be pathogenic in animals and humans as they may lead to various health problems, such as liver, kidney or nervous system damage, immunosuppression and carcinogenesis ${ }^{1}$. Because fungi are widespread in the environment, mycotoxins are considered unavoidable contaminants in foods and feeds. The mycotoxin

\footnotetext{
* To whom all correspondence should be addressed. Tel.:+96611-4769137; Fax: +96611-4769137;

E-mail: szargar@ksu.edu.sa
}

citrinin is one of the toxic secondary metabolites produced by Pencillium notatum. Contaminations of citrinin were reported in a number of agricultural commodities, foods, feedstuffs as well as biological fluids at geographically diverse locations ${ }^{2-10}$. This mycotoxin was first isolated from filamentous fungus Penicillium citrinum. ${ }^{11}$ It is also produced by other species of Penicillium ${ }^{12}$, Aspergillus ${ }^{13}$ and Monascus. ${ }^{14,15}$ Due to its antibacterial potential, citrinin was used as an antibiotic ${ }^{16}$ but soon was banned due to its nephrotoxic side effects in humans.

Rhazyastricta Decne (Harmal) is widespread in South eastern Areas of Saudi Arabia. It has antimicrobial properties. Its leaf extract is used as a remedy for sore throat and fever ${ }^{16}$. The 
genus Rhazya, belongs to the indole alkaloid-rich family Apocynaceae. Indole alkaloids exhibit numerous biological activities such as antitumor, antimicrobial and antihypertensive properties, and they are central nervous system stimulants ${ }^{17}$. A good amount of work regarding pharmacological, phytochemical, toxicological and to some extent biological activities of $R$. stricta has been reported. ${ }^{18,19}$ But more work needs to be done regarding its medicinal importance and taxonomic and ecological aspects. As the plant of $R$. stricta has immense potential as an antimicrobial due to the rich source of phytochemicals it possesses, therefore, such studies on biological activities particularly anti-microbial are recommended in various parts of the countries of Arabian Peninsula and the Indian subcontinent where it grows.

Response surface methodology (RSM) is a statistical technique used for the development and optimization of complex processes. ${ }^{20,21}$ RSM was selected and used to find the optimum conditions for maximum inhibition of citrinin and dry cell weight produced by fungus $P$ notatum. The technique has several advantages over conventional experimental or optimization methods in which one variable at a time is used. RSM provides a large amount of information and is more economical approach because; a small number of experiments are performed for monitoring the interaction of the independent variables on the response. In conventional optimization, the increase in the number of experiments necessary to carry out the research, leads to an increase in time and expenses as well as an increase in the utilization of reagents and materials for experiments. The equation of the model easily clarifies the effects for binary combinations of the independent variables. Box-Behnken design is advantageous because it does not contain any points at the extremes of the cubic region created by the twolevel factorial combinations that are prohibitively expensive or impossible to test because of physical constraints on experimentation. ${ }^{22}$ Medicinal plants represent an important health and economic component of biodiversity. In the present investigation the Box Behnken design was selected and used to optimize the aqueous extracts of tested medicinal plant, R. Decne, from Saudi Arabia on growth of $P$ notatum and its subsequent citrinin production.

\section{EXPERIMENTAL}

\section{Material and Methods}

Microorganisms and culture conditions

Citrinin-producing Penicillium notatum was obtained from the culture collection of the Microbiology Laboratory of King Khalid University Hospital, King Saud University, Riyadh; KSA. The fungal culture was maintained on slants of potato dextrose agar medium at $4^{\circ} \mathrm{C}$. The spores were suspended by growing the fungi on Petri dishes for 7 days at $25^{\circ} \mathrm{C}$ with potato dextrose agar (PDA) containing $50 \mathrm{mg} / \mathrm{L}$ of streptomycin. Later Spores were harvested by adding $10 \mathrm{ml}$ of sterilized distilled water on each plate. The spore suspension hence obtained was filtered using cheesecloth, and spores were counted using a haemocytometer and brought to a final concentration of $10^{5}$ conidia $/ \mathrm{ml}$. Collection and preparation of aqueous plant extracts

Literature survey was done and taxonomic studies of the herbarium specimens of the medicinal plants available at the National Herbarium of Saudi Arabia (Riyadh), and the herbarium of King Saud University (Pharmacy), were done by using long arm stereomicroscope. Leaves of the Rhazyastricta Decne were collected and washed under tap water. Then the leaves were dried at $60^{\circ} \mathrm{C}$ in hot air oven for 5 days and ground to make a powder and passed through 20 mesh sieve. 10 grams of powdered leaves were made soluble with $100 \mathrm{ml}$ distilled water at $200 \mathrm{rpm}$ for $5 \mathrm{~h}$ at room temperature. ${ }^{23}$ The remaining insoluble material was filtered by Whattman No.1 filter paper and centrifuged at $10,000 \mathrm{rpm}$ for $10 \mathrm{~min}$. The supernatant was collected and again passed through $0.45 \mu \mathrm{m}$ filter (Millipore) and stored at $-20^{\circ} \mathrm{C}$ for further use.

\section{Seed culture and fermentation}

The culture of $P$ notatum was grown on potato dextrose agar (PDA) slants and spore suspension $\left(4 \times 10^{6}\right.$ spores per $\left.\mathrm{mL}\right)$ was made in glycerol water solution $(15 \mathrm{~g} / \mathrm{L})$. The seed culture media used in this study were glucose $(20 \mathrm{~g} / \mathrm{L})$, glycerol (30 g/L), peptone (8 g/L), $\mathrm{NaNO}_{3}\left(2 \mathrm{~g} \mathrm{l}^{-1}\right)$ and $\mathrm{MgSO}_{4}(1 \mathrm{~g} / \mathrm{L})$ dissolved in water-soluble extract of soybean meal. All fermentation experiments were carried out in $250 \mathrm{ml}$ Erlenmeyer flasks containing $50 \mathrm{ml}$ of production media as per experimental design (Ahmad et al.2011).

Different concentrations of aqueous plant 
extract were added to liquid broth. $10 \mu \mathrm{l}$ amount from suspension (containing $10^{5} \mathrm{spore} / \mathrm{ml}$ of $P$ notatum) was inoculated in each flask and kept in rotary shaker at $200 \mathrm{rpm}$. The control contained production medium and $10 \mu \mathrm{l}$ of $P$ notatum suspension. The fungal mycelium was harvested by filtration by muslin cheese cloth to separate from liquid culture. The filtered biomass was then dried at $40^{\circ} \mathrm{C}$ for $24 \mathrm{~h}$ and the dry weight of mycelium was determined. Filtrates were stored in $4^{\circ} \mathrm{C}$ for carrying out citrinin extraction. All experiments consisted of three replicates, and the averages were determined.

\section{Extraction and quantification of citrinin}

The filtrates obtained from above experiment were used for extraction and estimation of citrinin. Briefly, the citrinin was extracted thrice with chloroform $(1: 1 \mathrm{v} / \mathrm{v})$. All the three extractions were pooled and concentrated in vacuum at $40^{\circ} \mathrm{C}$ using a rotary evaporator. All the concentrates were then diluted in mobile phase $(2 \mathrm{ml})$ and citrinin was estimated by HPLC.All the samples were filtered through a 0.22ìm disposable syringe filter (Micro Filtration Systems ${ }^{\circledR}$ ) prior to injection into the chromatograph. Aliquots (30 iL) were injected on HPLC column and analysis were carried out using a Shimadzu ${ }^{\circledR}$ Liquid Chromatograph, equipped with an LC-20AD pump, a Rheodine ${ }^{\circledR}$ injector, an SPD-20A UV detector, a CBM-20 ACommunications Bus Module, and a LC Solutions Workstation system. A reverse-phase Atlantis ${ }^{\circledR}$ dC 18 column $(150 \times 3.9 \mathrm{~mm}$, $5 \mathrm{ìm})$ was used, at room temperature. The mobile phase used was acetonitrile-water (75:25 v/v) and formic acid (2\%) with a flow rate of $1.5 \mathrm{~mL} / \mathrm{min}$ for an isocratic run of $10 \mathrm{~min}$. Absorbance of samples and standard was detected at $360 \mathrm{~nm}^{24}$ (Abramson et al., 1999). Retention times and peak areas were calculated by LC Solutions software. Evaluation of sample retention times with that of the standard identified the presence of citrinin in the samples. The relationships between peak area and the amount injected were linear over the ranges $2.5-50 \mu \mathrm{g}$.

\section{Optimization of experimental conditions Box-Behnken experimental design}

A response surface statistical experimental design was used to optimize the concentration of extract, incubation days and temperature. This design was based on a $3^{3}$ factorial design, three replicates of the central run, leading to 15 sets of experiments, enabling each experimental response to be optimized. The responses were investigated using a Box-Behnken statistical experimental design. The optimization process involves evaluating the response of the statistically designed combinations, estimating the coefficients by fitting the experimental data to the response function, predicting the response of the fitted model, and checking the adequacy of the model. All experiments were performed in standard order to minimize the effects of uncontrolled factors that may introduce a bias in the response. Before starting an optimization procedure, it is important to identify the crucial factors affecting the quality of the derived outcomes. The levels of the three factors evaluated in this design are listed in (Table 1). A three factor, three-Level Box-Behnken design was used for the optimization procedure, using the software Design Expert V 8.0.7.1. All other factors, for example volume of spore suspension, $\mathrm{pH}$ of the broth etc were maintained constant. The quality of the fitted model was expressed by the coefficient of determination $R^{2}$, and its statistical significance was checked by an $F$-test (analysis of variance) at the $5 \%$ significance level. The optimum processing conditions were obtained by using graphical and numerical analysis based on the criteria of the desirability function and the response surface. The experiment was finally repeated under the optimum values as per the point prediction tool of response surface methodology for concentration of extract, incubation period and temperature which should result in maximum inhibition of citrinin and dry cell weight production. These optimized values of tested parameters were validated $(n=6)$ and compared with control for citrinin and dry cell weight inhibition.

\section{RESULTSAND DISCUSSION}

\section{Design of the proposed assay and strategy for its development}

The proposed study was designed to optimize the most appropriate conditions for maximum inhibition of citrinin production and fungal biomass by using medicinal plant aqueous extract of $R$. Stricta Decne.The levels of inhibition of citrinin was assessed by HPLC in samples treated with extract of Rhazyastricta Decne and the percentage of inhibition compared to the control 
(Fig 1), similarly the inhibition in biomass was studied by dry cell weight and compared with control.

\section{Optimization of fermentation medium}

The key parameters most influencing on the inhibition of citrinin and fungal biomass, viz

Table 1. Levels of tested parameter for Box-Behnken design

\begin{tabular}{lcccc}
\hline \multirow{2}{*}{ Independent factors } & Unit & Symbol & \multicolumn{2}{c}{ Levels } \\
\cline { 4 - 5 } & & & Low & High \\
\hline Extract Concentration & mg/L & $\mathrm{A}$ & 2 & 16 \\
Incubation Time & Days & $\mathrm{B}$ & 8 & 24 \\
Temperature & ${ }^{\circ} \mathrm{C}$ & $\mathrm{C}$ & 20 & 30 \\
\hline
\end{tabular}

$\mathrm{mg} / \mathrm{L}$ is milligram per litre and ${ }^{\circ} \mathrm{C}$ is incubation temperature in degree centigrade

Table 2. The Box-Behnken design of three variables

\begin{tabular}{|c|c|c|c|c|c|c|c|}
\hline \multirow[t]{2}{*}{ Runs } & \multirow{2}{*}{$\begin{array}{c}\text { Extract } \\
\text { Conc. (mg/L) }\end{array}$} & \multirow{2}{*}{$\begin{array}{c}\text { Factors } \\
\text { Incubation Days }\end{array}$} & \multirow{2}{*}{$\begin{array}{c}\text { Temperature } \\
\left({ }^{\circ} \mathrm{C}\right)\end{array}$} & \multicolumn{2}{|c|}{ Citrinin (mg/L) } & \multicolumn{2}{|c|}{ Fungal biomass (mg) } \\
\hline & & & & Actual & Predicted & Actual & Predicted \\
\hline 1 & 2 & 8 & 25 & 2.5 & 5.375 & 82 & 77.5 \\
\hline 2 & 16 & 8 & 25 & 0 & 1.25 & 55 & 48.25 \\
\hline 3 & 2 & 24 & 25 & 247 & 245.75 & 383 & 389.75 \\
\hline 4 & 16 & 24 & 25 & 103 & 110.87 & 171 & 175.5 \\
\hline 5 & 2 & 16 & 20 & 179 & 185.81 & 293 & 288.87 \\
\hline 6 & 16 & 16 & 20 & 151 & 148.68 & 212 & 210.12 \\
\hline 7 & 2 & 16 & 30 & 217 & 219.31 & 349 & 350.87 \\
\hline 8 & 16 & 16 & 30 & 135 & 128.18 & 182 & 186.12 \\
\hline 9 & 9 & 8 & 20 & 1 & 2.06 & 65 & 73.62 \\
\hline 10 & 9 & 24 & 20 & 186 & 180.43 & 280 & 277.35 \\
\hline 11 & 9 & 8 & 30 & 1 & 6.56 & 74 & 76.65 \\
\hline 12 & 9 & 24 & 30 & 190 & 188.93 & 321 & 312.37 \\
\hline 13 & 9 & 16 & 25 & 155 & 159.33 & 182 & 183.33 \\
\hline 14 & 9 & 16 & 25 & 160 & 159.33 & 178 & 183.33 \\
\hline 15 & 9 & 16 & 25 & 163 & 159.33 & 190 & 183.33 \\
\hline
\end{tabular}

$\mathrm{mg} / \mathrm{L}$ is milligram per litre and ${ }^{\circ} \mathrm{C}$ is incubation temperature in degree centigrade

Table 3. Analysis of variance of calculated model for citrinin absorbance

\begin{tabular}{lcc}
\hline & Citrinin & Biomass \\
\hline Model (Mean Square) & 11119.86 & 17357.54 \\
Residual & 327.48 & 409.92 \\
$R^{2}$ & 0.9967 & 0.9974 \\
$F$ & 169.78 & 211.72 \\
$p$-value & 0.0001 & 0.0001 \\
\pm SD & 8.10 & 9.05 \\
RSD & 6.42 & 11.65 \\
*Adequate Precession & 38 & 46.20 \\
\hline
\end{tabular}

*Adequate Precision measures the signal to noise ratio. A ratio greater than 4 is desirable. This model can be used to navigate the design space. concentration of plant extract, incubation days and temperature were studied. The results of experimental runs are summarized in (Table 2). Data collected from experimental runs were analyzed by using the software Design Expert V 8.0.7.1and fitted to nonlinear quadratic models for citrinin inhibition and fungal biomass analysis. The model was validated by analysis of variance (ANOVA). The statistical analysis showed that the model represents the phenomenon quite well and the variation of the response was correctly related to the variation of the factors (Table 3).

In general, exploration and optimization of a fitted response surface may produce poor or misleading results, unless the model exhibits a good 
fit, which makes checking of the model adequacy essential..$^{25}$ The F-ratio in this table is the ratio of the mean square error to the pure error obtained from the replicates at the design centre. The significance of the F-value depends on the number of degrees of freedom (DF) in the model and is shown in the P-value column (95\% confidence level). Thus, the effects lower than 0.05 are significant. ${ }^{26}$ (The P-value is used as a tool to check the significance of each coefficient and the interaction strength between variables. ${ }^{27}$ The higher the significance, the better the degree of correlation between the observed and predicted values. ${ }^{28}$ Total extract concentration, incubation days and temperature content were significantly affected.

An experimental design of 15 runs containing 3central points was made according to Box-Behnken of response surface methodology to optimize these medium parameters. The individual and interactive effects of these parameters were studied during fermentation. The response was measured in terms of actual factors of inhibition of citrinin and dry cell weight. Data collected from experimental runs were analyzed by using the software and fitted to nonlinear quadratic models for citrinin and dry cell weight inhibition. The regression analysis was carried out to fit mathematical models to the experimental data aiming at an optimal region for the responses studied. Predicted response for the yield of each response could be expressed by the following polynomial quadratic equation in terms of actual values: The significance of each coefficient is listed in Table 4. The fitted model equation is:

Citrinin inhibition $(\mathrm{mg} / \mathrm{L})=-235.00383+14.28954 \mathrm{~A}$ $+53.13579 \mathrm{~B}-13.82024 \mathrm{C}-0.63170 \mathrm{AB}-0.38571 \mathrm{AC}$ $+0.025000 \mathrm{BC}+0.048895 \mathrm{~A}^{2}-1.15007 \mathrm{~B}^{2}+0.35083 \mathrm{C}^{2}$ Dry cell weight $(\mathrm{mg}):+799.41582+8.22704 \mathrm{~A}$ $+37.31324 \mathrm{~B}-83.68810 \mathrm{C}-0.82589 \mathrm{AB}-0.61429 \mathrm{AC}$ $+0.20000 \mathrm{BC}+0.64711 \mathrm{~A}^{2}-0.66081 \mathrm{~B}^{2}+1.75833 \mathrm{C}^{2}$

This multiple nonlinear model resulted in three response surface graphs each for citrinin and dry cell weight. Point predict ion tool of the software was used to calculate maximum inhibition of citrinin and dry cell weight. Finally the optimum values as per the point prediction tool were found to be $13.16(\mathrm{mg} / \mathrm{L})$ for concentration of extract, ten days of incubation period and temperature $25^{\circ} \mathrm{C}$ which resulted in maximum inhibition of citrinin (56.17 mg/L) and dry cell weight production (79.42 $\mathrm{gm})$. These optimized values of tested parameters were validated under similar conditions $(n=6)$ as discussed in material and methods and compared with control citrinin production ( $286 \mathrm{mg} / \mathrm{L})$ and dry cell weight production (408.65 gm). An average of $80.67 \pm 0.75 \%$ inhibition of citrininand $81.65 \pm 2.56 \%$ of dry cell weight was obtained in anoptimized medium at $10^{\text {th }} \mathrm{d}$ of fermentation with $98.41 \%$ and $94.37 \%$ validity, respectively.

The relationship between independent and dependent variables is illustrated in threedimensional representation of the response surfaces and one factor plots generated by the models for citrinin and biomass (Fig. 2). Figure 2A and Bshows the effect of extract concentration and

Table 4. Regression coefficients and their significance in the quadratic model

\begin{tabular}{lccccc}
\hline \multirow{2}{*}{ Terms } & \multicolumn{2}{c}{ Citrinin } & & \multicolumn{2}{c}{ Biomass } \\
\cline { 2 - 3 } \cline { 5 - 6 } & Coefficient Estimate & P-value & & Coefficient Estimate & P-value \\
\hline Intercept & 159.33 & $<0.0001$ & & 183.33 & $<0.0001$ \\
A- Extract Conc. & 32.06 & $<0.0001$ & & 60.87 & $<0.0001$ \\
B- Incubation Time & 90.18 & $<0.0001$ & & 109.87 & $<0.0001$ \\
C- Temperature & 3.25 & 0.3075 & & 9.5 & 0.0312 \\
AB & 35.37 & 0.0003 & & 46.25 & 0.0002 \\
AC & 13.5 & 0.0206 & & 21.5 & 0.0051 \\
BC & 1 & 0.8146 & & 8 & 0.1375 \\
$A^{2}$ & 2.39 & 0.5941 & & 31.70 & 0.0011 \\
$B^{2}$ & 73.61 & $<0.0001$ & & 42.29 & 0.0003 \\
$C^{2}$ & 8.77 & 0.0918 & 43.95 & 0.0002 \\
\hline
\end{tabular}

$\mathrm{p}<0.05$ is significant, $\mathrm{p}<0.0001$ is considered highly significant (Independent Samples T-Test between the control and the treated groups with drug extract). 

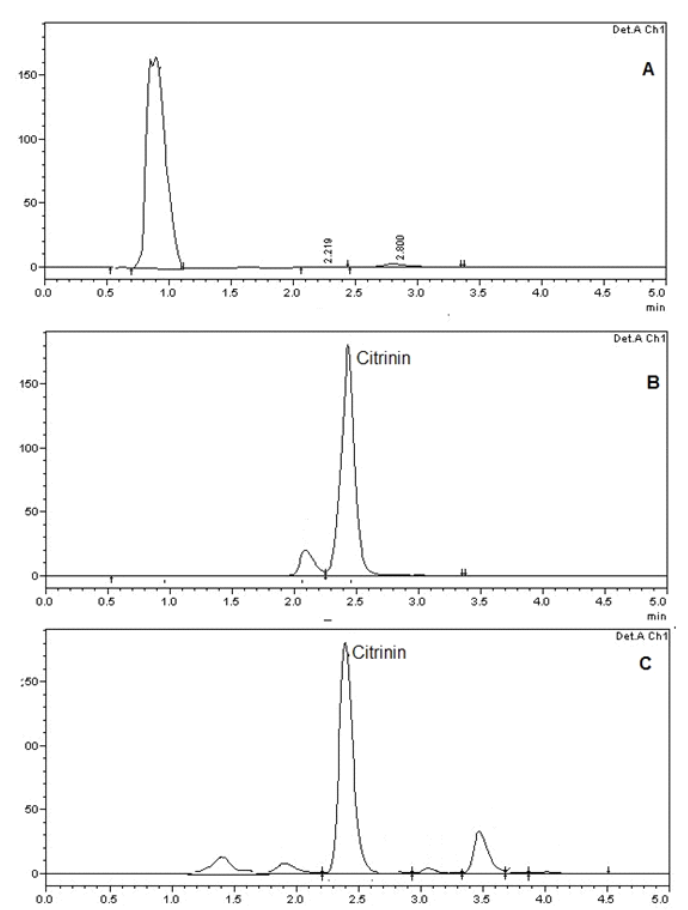

Fig. 1. A typical HPLC chromatogram of citrinin
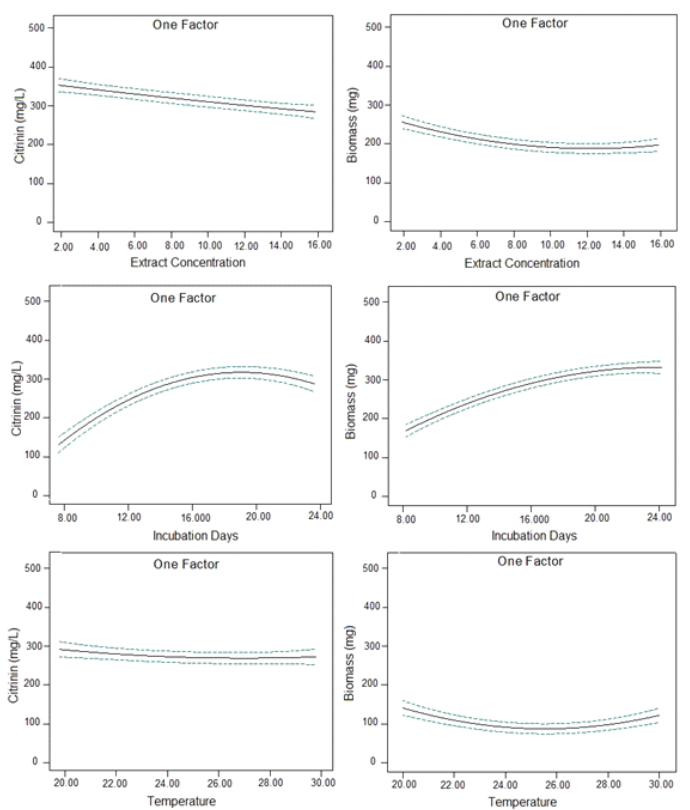

Fig. 3. Effect of factors like extract concentration, incubation days and temperature individually on fungal biomass and citrinin production
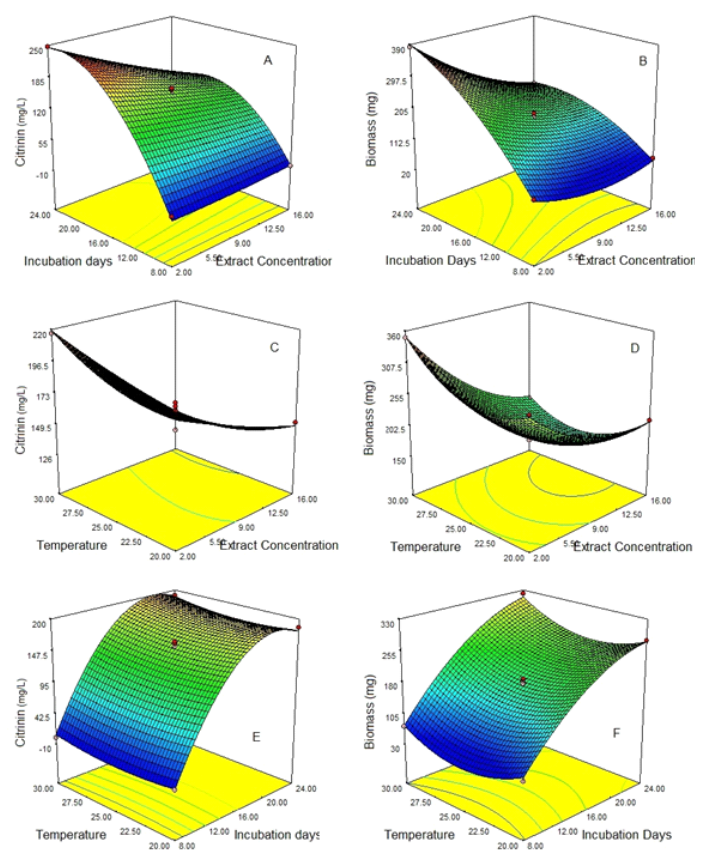

Fig. 2. Response-surface graphs representing the effect of extract concentration, incubation time and temperature on the responses

incubation days on citrinin and fungal dry cell weight at a constant temperature $25^{\circ} \mathrm{C}$. It is apparent from the figure that citrinin and fungal dry cell weight inhibition increased with increasing extract concentration and number of incubation days. Figure 2C and Dshows the effect of temperature and concentration of extract on inhibition of citrinin and fungal dry cell weight at fixed incubation period of 16 days. Figure $2 \mathrm{E}$ and $\mathrm{F}$ shows the effect of temperature and incubation days of citrinin and fungal dry cell weight at fixed concentration plant extract $(9 \mathrm{mg} / \mathrm{L})$. Figure 3AI, AI1;BI, BI1and CI, CI1 shows the effect of individual factors for extract concentration, incubation days and fermentation temperature of both citrinin and fungal dry cell weight is evident from the figures that both these variables have direct effect citrinin concentration and fungal biomass.

\section{CONCLUSION}

The present study was designed to identify the antifungal activity of natural products 
for inhibition of mycotoxins in foodstuff. The antifungal potential of the $R$ serata Decane was studied for the first time for preservation of food stuffs from production of citrinin. Citrinin is a proven hepato nephrotoxic agent and hence need to be inhibited. The effect of individual variables on inhibition of citrinin and fungal dry cell weight was also studied using Box-Benkhen response surface methodology. Optimum conditions for maximum inhibition of mycotoxin citrinin were also developed. The results obtained using response surface predictions were in good agreement with the experimental results. Therefore, Box-Behnken statistical design used in determining the optimum experimental conditions such as extract concentration, incubation days and temperature was reliable and cost effective.

\section{ACKNOWLEDGMENTS}

This research project was supported by a grant from the 'Research Center of the Center for Female Scientific and Medical Colleges', Deanship of Scientific Research, King Saud University.

\section{REFERENCES}

1. Bennett J W\& Klich M, Clin Microbiol Review 2003; 16: 497-516.

2. Abramson D, Hulasare R, White N D G, Jayas D S \& Marquardt R R, J Stored Prod Res 1999; 35: 297-305.

3. Bailly J D, Querin A, Le Bars-Bailly S, Benard G \& Guerre P, J Food Protection 2002; 65: 13171321.

4. CAST, Mycotoxin: risks in plant, animal, and human systems. Council of Agricultural Science and Technology Task force rep. No. 139, CAST, Ames, IA, 2003.

5. Comerio R, Fernandez PintoV E \& Vaamonde G Inter J Food Microbiol 1998; 42: 219-223.

6. Gimeno A \& Martins M L, J AOAC intern 1983; 66: 85-91.

7. Heber D, Lembertas A, Lu Q Y, Bowerman S \& Go V L W, J Altern Complement Med 2001; 7: 133-139.

8. Kpodo K, Sorensen A K \& Jakobsen M, Food
Chem 1995; 56: 147-153.

9. Meister U, Eur Food Res Technol 2004; 218: 394-399.

10. Phillips R D, Hayes A W \& Berndt W O, $J$ Chromatogr 1980; 190: 419-427.

11. Hetherington A C \& Raistrick H, Thom. Philos Trans. R.Soc.Lond. B. Biol. Sc 1931; 220: 269 297.

12. Ei-Banna A A, Pitt J I \& Leistner L, System Appl Microbial 1987; 10: 42-46.

13. Kurata H, Mycotoxins and mycotoxicoses (In Pohlandm A E, Dowell V R \& Richards J L eds) 1990; 249-259, New York, Plenum Press,USA.

14. Blanc P J, Loret M O \& Goma G, Letters 1995; 17: 291-294.

15. Li F, Xu G, Li Y \& Chen Y, Wei Sheng Yan Jiu 2003; 32: 602-605.

16. Rahman M A, Mossa J S, Al-Said M S \& AlYahya M A, Fitoterapia 2004; 75: 149-161.

17. Verpoorte R, In Alkaloids: Biochemistry, Ecology and Medicinal Applications. (Roberts M F, Wink M eds), Plenum Press, New York, 1998; 397433.

18. Marwat S K, Fazal-ur-Rehman, Usman K, Shah S S, Anwar N \& Ullah I, Afr J Microbiol Res 2012; 6: 1629-1641.

19. Ali B H, Alqarawi A A, Bashir A K \& Tanira M O, Phytother Res 2000; 14: 469-471.

20. Ferreira S L, Bruns R E, Ferreira H S, Matos G D, David J M, Brandao G C, da Silva E G, Portugal L A, dos Reis P S, Souza A S \& dos Santos W N, Anal Chimica Acta 2007; 597: 179186.

21. Bezerra M A, Santelli R E, Oliveira E P, Villar L S \& Escaleira L A, Talanta 76, 965-977.

22. Mason R L, Gunst R F \& Hess J L, Statistical Design and Analysis of Experiments. 2003; 586 (Hoboken, NJ), Wiley.

23. Razak M FA, Aidoo K E \& Candilish A G G Mycopathy 2009; 167: 273- 286.

24. Wong H C \& Koehler P E, J Food Sci 1981; 46: 589-592.

25. Liyana-Pathirana C \& Shahidi F, Food. Chem. 2005; 93: 47-56.

26. Morelli L L L \& Prado M A, Ultra Sonochem 2012; 19: 1144-1149.

27. Karacabey E \& Mazza G, Food Chem 2010; 119: 343-348.

28. Ravikumar K, Ramalingam S, Krishnan S \& Balu K, Dyes and pigments 2006; 70: 18-26. 